\title{
SOLIA, CONTOSOLIA Y EL NOMBRE DEL ZUJAR
}

Iin un trifinizm encontrado nuy próximo a Villanueva de Córdoba y publicado por el padre Fita $^{1}$ se fijan los límites de los solienses con los municipios de Sacilis y Eipora (I'edro Abad y Montoro). Tenemos, pues, constancia de los límites orientales de Solia, que debió de ser una ciuclad importante, porque vuelve a aparecer en las Actas del Concilio de Iilvira. Quedan, pues, por fijar, sus limites meridionales y occidentales.

Iin cuanto a los meridionales, el problema está definitivamente resueito por una nueva inscripción que establece la existencia en la zona del valle de los Pedroches de un nuevo municipio, Baedro, que es, sin duda alguna, Pedrochic ${ }^{2}$. Quedan, pues, los límites occidentales.

Creemos que este problema debe desligarse del de la localización de la ciudad de Solia. Para ésta se han propuesto dos emplazamientos: ya hacia el occidente del valle de los Pedroches (Belalcázar o Hinojosa del Duque), ya más recientemente $y$, con mucha más probabilidad de acierto ${ }^{3}$, en el término de İil Guijo, en la finca Majadalaiglesia, donde existen los restos romanos más importantes de la zona, que formaron una ciudad que llegó a la época medieval con cl nombre de El Villar de Santa María.

Pero los límites del territorio de los solienses son cosa muy diferente y la localización de Solia en El Guijo no parece argumento decisivo contra la extensión de éstos hacia el occidente, hasta el Zújar. Como tampoco, de ser esto verdad, es suficiente para llevar igualmente la capital hacia

$1 B R A H$, I9I3, LX, p. 44. Antes habia sido publicado por HÜBNER en $C I L, I I$, 2349, pero muy imperfectamente. Sin embargo, A. Tovar, Zephyrus, r962, XIII, 1. 106 , cree que Baedro scría $\mathrm{L} 1 \mathrm{l}$ Viso, donde fue encontrada la inscripción.

2 Cf. JUUN OCAÑa y ANTONio Rodriguez AdRados en el libro del primero, llisloria de la villa de Pedroche y su comarca, Córdoba, I962, P. I32 ss., donde por primera vez se publica la inscripción cn cuestión y se cstablece la identificación de Bacilro y I'ciroche.

3 Cf. obra citada, p. I 35 . Lin clla se da una buena descripción del yacimiento. 
el oeste, como se ha hecho a veces. Al norte de Baedro queda una zona por la que se establece la continuidad entre el este y el oeste del territorio de los solienses.

Querríamos aqui fundamentar la hipótesis de que dichos límites llegaban efectivamente al Zújar. La argumentación es de carácter lingüístico: la identificación de Solia con el nombre del Zújar; la relación del nombre de Solia con el de Contosolia, que es Magacela, junto a Don Benito. El relacionar Solia con Contosolia es antiguo, así como el deducir de Solia el nombre de Zújar ${ }^{1}$; pero es uri tema que ha sido tratado un poco de pasada. Querríamos precisarlo, haciendo ver que Contosolia significa "lo que está a los largo del Solia", dando datos para la etimología Solia > Ziijar y sugiriendo que Solia, de significar el río, pasó a designar la región que se encuentra al este del mismo y luego, indudablemente, su capital. Al mismo tiempo, poniendo de relieve que todos estos nombres son celtas o, en todo caso, indoeuropeos, relacionaremos este hecho con datos ya conocidos sobre la población indoeuropea de esta zona.

Contosolia figura en el Itinerario de Antonino ${ }^{2}$ como una mansión en la calzada de Emerita a Laminium, correspondiendo a la actual Magacela ${ }^{3}$, cerca de Don Benito. En mi opinión, conto- es un derivado con -to del adverbio y preposición *kom 'junto a', bien conocido en celta: es, por lo tanto, 'próximo' o 'al lado de', 'enfrente', y Contosolia un compuesto posesivo completamente normal que significa, como se ha indicado, 'que tiene a Solia próxima', 'próxima a Solia' (o 'enfrente de Solia').

No está testimoniado directamente el adjetivo *komto-, pero sí formas derivadas de él. Ante todo tenemos Contienses, hoy Günzburg, y Contionacum o Contiacum, Contium, hoy Conz, junto a Tréveris; en uno y otro caso se trata de ciudades situadas en la confluencia de dos ríos, es decir, su etimología puede compararse a la de Coblenza (Koblenz), que viene de Confluentia. Ambos topónimos se encuentran en territorio céltico antiguo. Sobre la base de ellos podemos, si no me equivoco, atribuir al celta $\longrightarrow$ a una lengua indoeuropea en todo caso- el elemento Cont- de diversos antropónimos de Galia, Lusitania y Celtiberia: Conto-

1 Cf. ya Fira, l. c., p. 5 I; I'R. Juan Ruiz, La Ilustre y Noble Villa de Hinojosa del Duque. Jetez de la Irroutera, 1922, pp. 82-83 (citado por OCAÑa-R. AdRados, ob. cit., p. $\left.\mathrm{I}_{4} \sigma\right)$.

$2,14,5$.

3 Cf. GulirRa, Disc. de contcstacion a Saavedra, p. 9I; HÜDNER, RE, IV, I, col. II 60 . 


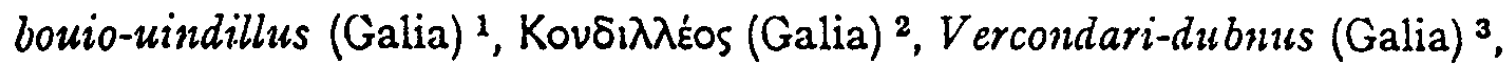
Senocondius (Galia) ${ }^{4}$, Contari (genit.; Lusitania) ${ }^{5}$, Continains (Lusitania) ${ }^{6}$, Cuntibus (Lusitania) ${ }^{7}$, Contobris (Celtiberia) ${ }^{8}$, Contizs (Galia $^{2}$ Cisalpina, ya cristiano) ${ }^{9}$.

De otra parte, en lenguas celtas tenemos testimoniado *kmita (air. cèt, agal. cont, etc.) 'con', 'junto a, a lo largo de', que también se encuentra en gr. kolvós. Y derivados de *kom paralelos a *komto- son gr. kará, o. comono 'comitia' y *komtero-, de donde lat. contra (cf. supra Contari).

En suma, nos encontramos con un ambiente indoeuropeo y muy probablemente céltico. Iisto se confirna también por la propia difusión de Solia, aunque aqui el terreno es más oscuro.

En Holder, Altkclischer Sprachschatz, encontramos testimoniado Solia, así como Solicia, Soliacus, ctc., y siempre o casi siempre en territorio céltico; también el gentilicio Solius. Concretamente, hay un topónimo Solia en el valle de Calmars (Bajos Alpes), y varios gentilicios Solius - Solia en Madrid, Brescia, Maguncia, York; Soliacum en las Galias varias veces; una diosa Solimärā en Bourges; etc. Resulta completamente claro que se trata de una formación indoeuropea difundida muy principalmente en el ambiente lingüístico celta; aunque no es imposible que hubiera pertenecido ya al "alteuropäisch" precelta o como quiera llamársele. Pues, en todo caso, esta formación en -ia tiene un aspecto claramente indoeuropeo.

Este ambiente indoeuropeo, más o menos definidamente celta, del NO. de Córdoba y zona limítrofe de Badajoz contrasta con el puramente ibérico de Sacilis, Epora y Baedro, que limitan Solia por el İ. y S. Nos hallamos, pues, con un enclave indoeuropeo en una zona de características muy distintas de las de la llanura andaluza y cuyas aguas vierten al Guadiana, hacia el $\mathrm{N}$. Nuestras conclusiones pueden apoyarse, creemos, con un conocido pasaje de Plinio ${ }^{10}$ en que distingue, en la Bacturia o zona

\footnotetext{
1 Cf. ScInidr, $Z C P h, 1957$, XXVII, p. 183.

2 Dotrin, La langue gauloise, p. 4 I y p. 4 , n. 2.

3 Ibid., p. 33.

1 Ibid., p. 59.

b L. AlBERTOS, Emerita, I960, XXVIII, p. 296. Cree que se trata de un nombre compuesto.

- Palomar, La onomástica personal prelatina de la antigua Lusitania. Salamanca, 1957, p. II9 s.

$7 \quad I b i d .$, p. 133 .

8 En DIODORO, III 24. Es posiblemente Contrebia; en todo caso el sentido es el mismo: se trata de *Conto-bhgrh-s 'ciudad unida', compuesto determinativo.

- CIL II 6253, 8.

30 NII III I, I3-I4.
} 
septentrional de la Bética, una conarca limítrofe con Lusitania habitada por los celtici y otra, limítrofe con Lusitania y la Tarraconense (es decir, más oriental), habitada por los turduli. A la primera corresponde evidentemente Contosolia, y también sin duda Solia. L,os topónimos de una y otra zona que da I'linio no permiten una clara y tajante distinción de las dos zonas, pero no hay nada que impida la admisión de que la zona céltica penetraba en el valle de los Pedroches, estando linitada al S. por Regina y Mellaria, y al N. por Sisapo. Mirobriga, próxima a Contosolia, y que Plinio da como perteneciente a los túrdulos, es en realidad claramente celta. En suma, creemos que la zona céltica que bordeaba la Lusitania hasta la confluencia del Guadiana y Zújar (con Ugultunia, Curiga, Segeda, etc.) se extendía con Solia al otro lado de este río.

Al llegar aquí tenemos que llamar la atención sobre el hecho extraño de que Contosolia tome su nombre de su proximidad a Solia. Iista proximidad es sólo relativa: en realidad de Magacela (Contosolia) a Pedroche (cn el centro del valle de Solia) hay en línea recta casi cien kilómetros. I,o más verosínil es que Solia designe, en el origen, más un territorio que una ciudad; territorio cuyos límites por el E. y S. nos dan el trifinium y la inscripción mencionados al comienzo y, por el $\mathrm{N}$. y $\mathrm{O}$. debe de quedar a cierta distancia de Contosolia. Efectivamente, el establecimiento de los pueblos indoeuropeos en la Península tiene lugar a base de tribus y organizaciones gentilicias y no de ciudades, que son lo secundario. Pero, aun así, resulta extraño que un territorio sea denominado por sus pobladores sobre la base de un territorio vecino. Sólo hay, en mi opinión, una explicación a este hecho: que dicho territorio vecino reciba su nombre de algún detalle geográfico que pueda también servir de punto de referencia al pueblo de al lado.

En suma: proponemos que Solia no sólo ha designado una región (el valle de los Pedroches) y, luego, la ciudad principal de la misma; sino que, al tiempo, era el nombre del accidente geográfico que separa dicho valle de la región de Contosolia: el río Zújar, que corre de sur a norte, como había sido ya sugerido. O sea, Solia es el Zújar y la región del Zújar, al este del mismo; Contosolia es la región más allá del Zújar, en la orilla opuesta de la región denominada con el nombre del río.

Para hacer verosímil esta hipótesis, conviene sentar dos puntos de apoyo diferentes: que Solia pudo ser un hidrónimo - el paso de un hidrónimo a topónimo es demasiado conocido para tener que ser justificado- y que Solia pudo dar Zújar en español moderno.

r. Il primer punto quedaría completamente claro si se admitiera la identidad de la raiz *sol con *sal, que aparece en nombres de ríos en el territorio indocuropeo occidental $y$, más concretamente, en el ámbito 
céltico. *Sal significa reconocidamente 'agua' y en Hispania se encuentra en Salo (el Jalón), *Salmantia (el Tormes, cf. Salmantica), *Salia (cf. Saja, Sallent), etc.; cf. en Suiza *Salantia (Salance), ctc. ${ }^{2}$. La relación entre las dos raíces no ha sido nunca propuesta, que sepamos; pero, dado que cada día resulta mús claro que a no es una vocal indoeuropea ${ }^{2}$, no veo mancra de evitarla. * Sal nace sin duda de una forma de grado cero de *sol: *sol > sal. Concretamente, es el grado cero el que esperamos en formas sufijadis como *Salo, Salmant-, *salant-. Iin cuanto a las formas con -ion, es sabido que la raíz lleva ya el grado pleno, ya el cero.

2. El Zújar es el único río importante entre Solia y Contosolia y resulta verosímil a priori que sea el río designado antiguamente como Solia. De otro lado, 10 parece tener etimología árabe ${ }^{3}$. Sin embargo,

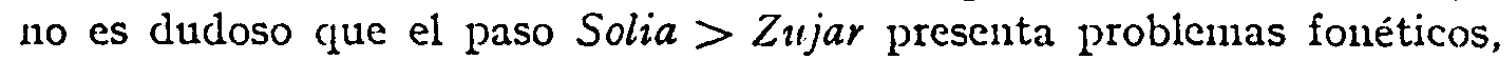
derivados de tratarse de una evolución fonética en que ha podido intervenir un dialecto mozárabe y, luego, una arabización y una castellanización del nombre. Por todo cllo la etimología que proponemos del \%ujjar crecmos que, si no segura, es al menos defendible.

Habrímos de partir evidentemente de una forma *Soliara; el paso por el árabe explicaría tanto la $z$, transcripción frecuente del xin árabe que a su vez transcribia la $s$ romana o prerromana ${ }^{4}$, como la caída de la $-a$ final, que es normal ${ }^{5}$. La forma *Soliara (también podría ser *Soliaro) es frente a Solia una de tantas variantes con sufijo átono existentes en la toponimia y el vocabulario prerromano y aun latino; Menéndez Pidal, que ha estudiado el fenómeno ${ }^{6}$, le atribuye un origen prerromano. Por lo demás, conviene notar que en fuentes cristianas del siglo XIV se le llama indistintamente Zuxa, Zuja, Suxa y Suja ${ }^{7}$ y que la primera forma, si realmente existe, remonta directamente a Solia.

Pero esto no explica todo, porque resulta claro que el paso de $*$ Soliara a Zújar requiere la intervención de un dialecto románico, el mozá-

I Cf. 'lovar, Topúnimos con -nt en Hispania y el nombre de Salamanca. Actes 5 e Congr. Topon.. Salamauca, I958, II, p. 95 ss.

2 Cf. sobre esto mi libro Estudios sobre las laringales indoeuropeas. p. Io2 ss.

3 No figura en AsIn, Contribución a la toponimia árabe de España. Madrid I940.

- Cf. Sancins Guarner en Enciclopedia Lingïistica Hispánica, I, Madrid, I960, p. 3i 8; Panón en Estudios Menéndez Pidal, IV, Madrid, 1953, p. 2r8. Pién-

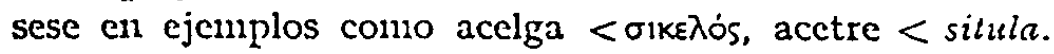

s Sancirs Gunrnirir, l. c., p. 309.

- Cf. Toponimia Romanica Hispana. Madrid, 1952, p. 69 ss.

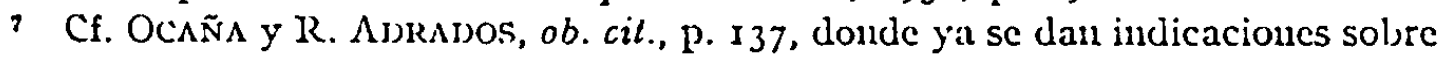
cl aspecto fonćtico cu la ctimología. 
rabe, del cual ha tomado la forma el árabe. El grupo li latino da en mozárabe $l$ lateral, según se admite normalmente; es decir, que la $j$ es un resultado de la castellanización del topónimo después de la Reconquista, como en tantos otros casos ${ }^{1}$. Sin enbargo, Amado Alonso ha postulado que el paso $l i>j$ es propiamente mozárabe ${ }^{2}$.

$\Lambda$ sí, la única dificultad real que existe para mi etimología es la evolución $0<u$. El tratamiento de $e$ y $o$ en mozárabe es un problema debatido, pues hay ejemplos contradictorios, con y sin diptongación. De todas formas, los ejemplos ante $l_{i}$ no presentan diptongación: cf. follar 'hojaldre', orelya 'oreja', etc.; es decir, el mozárabe parece proceder en esto igual que el castellano. Si hay Zujar y no *Zojar, ello se debe sin duda al paso de la palabra por el árabe; es un caso comparable al de almuld derivado de lat. modius y otros.

Como se ve, si no es absolutamente seguro que Solia es primitivamente el río Zújar y, luego, el valle y la ciudad al E. del mismo, sí es una hipótesis que merece ser considerada. Y lo que resulta de todo punto claro es que Solia, situada al li. de dicho río, y Contosolia, al O., testimonian la población celta de toda esta zona, confirmando y completando el testimonio de Plinio.

Francisco R. Adrados.

1 MENÉNDez Pidal, en Orígenes del Español, en $\S 50,4$.

$2 R F H, 1946$, VIII, p. 4 I. 